\title{
A prática de enfermeiros no contexto das comunidades quilombolas ${ }^{a}$
}

\author{
Nurses' practice in the context of quilombolas communities \\ La práctica de enfermeras en el contexto de las comunidades de quilombolas
}

\author{
Lilian Cristina Rezende ${ }^{1}$ (I) \\ Carolina da Silva Caram ${ }^{1}$ (i) \\ Luana Silva Rezende ${ }^{1}$ (1) \\ Kênia Lara Silva ${ }^{1}$ (D) \\ Maria José Menezes Brito ${ }^{1}$ (1)
}

1. Universidade Federal de Minas Gerais, Escola de Enfermagem, Departamento de Enfermagem Aplicada. Belo Horizonte, MG, Brasil.
Autor correspondente: Lilian Cristina Rezende E-mail: lilianc.enf@gmail.com

Recebido em 12/05/2020.

Aprovado em 29/06/2020.

DOl:https://doi.org/10.1590/2177-9465-EAN-2020-0151

\section{RESUMO}

Objetivo: Compreender as particularidades de comunidades quilombolas para a construção da prática do enfermeiro na Estratégia Saúde da Família, sob o prisma da Ética Feminista. Método: Estudo de caso único integrado qualitativo, sustentado no referencial epistemológico da ética feminista. A coleta ocorreu ente fevereiro-junho/2018 por meio de entrevistas individuais, coletivas e observação, com a participação de 59 quilombolas e 07 enfermeiros da equipe de Estratégia Saúde da Família, na Região Metropolitana de Belo Horizonte. Dados submetidos à análise de conteúdo com auxílio do software ATLAS.ti 8.0 Resultados: As particularidades dos quilombolas são identificadas nos aspectos da afrodescendência, como os vínculos de parentesco e manifestações culturais e religiosas. Viver na comunidade significa compartilhamento e preservação cultural. A prática do enfermeiro, nessas comunidades, é construída por meio do encontro do indivíduo/família/coletividade, do fortalecimento do vínculo e do respeito e valorização da cultura e modos de vida das pessoas. Reitera-se uma prática de compartilhamento de responsabilidade, na dualidade construída entre quilombolas e profissionais. Conclusões e implicações para a prática: A prática do enfermeiro em comunidades quilombolas é pautada no reconhecimento de especificidades sociais e culturais de grupos com ancestrais do continente africano e contribui para o fortalecimento da integração do cuidado no encontro indivíduoprofissional, com responsabilidades compartilhadas.

Palavras-chave: Enfermagem; Cultura; Estratégia Saúde da Família; Grupo com Ancestrais do Continente Africano; Grupos Minoritários.

\section{Abstract}

Objective: To understand the particularities of quilombola communities for the construction of the nurses' practice in the Family Health Strategy, from the perspective of Feminist Ethics. Method: Qualitative single integrated case study, based on the epistemological framework of feminist ethics. The collection took place between 2018 February-June by means of individual, collective interviews and observation with the participation of 59 quilombolas and 07 nurses from the Family Health Strategy team, in the Metropolitan Region of Belo Horizonte. Data submitted to content analysis with the aid of ATLAS.ti 8.0 software. Results: The particularities of quilombolas are identified in the aspects of afrodescendence such as kinship ties, and cultural and religious manifestations. Living in the community means sharing, and cultural preservation. The nurses' practice is built, in these communities, by means of the individual/family/community, by strengthening of interpersonal relationships and of the respect and appreciation of people's culture and ways of life. A practice of sharing responsibility is reiterated, in the duality built between quilombolas and professionals. Conclusions and implications for practice: The practice of nurses in quilombola communities is based on the recognition of social and cultural specificities of groups with ancestors from the African continent and contributes to strengthening the integration of care in the individual-professional meeting with shared responsibilities.

Keywords: Nursing; Culture; Family Health Strategy; African Continental Ancestry Group; Minority Groups.

\section{Resumen}

Objetivo: Comprender las particularidades de las comunidades quilombolas para la construcción de la práctica de las enfermeras en la Estrategia de Salud Familiar, desde la perspectiva de la ética feminista. Método: Estudio de caso cualitativo integrado único, basado en el marco epistemológico de la ética feminista. La colección se realizó entre febrero y junio de 2018 por medio de entrevistas individuales y colectivas y observación con la participación de 59 quilombolas y 07 enfermeras del equipo de Estrategia de Salud Familiar, en la Región Metropolitana de Belo Horizonte. Datos enviados al análisis de contenido con la ayuda del software ATLAS.ti 8.0. Resultados: Las particularidades de los quilombolas son identificados en los aspectos del afrodescendiente, como los lazos de parentesco y las manifestaciones culturales y religiosas. Vivir en la comunidad significa compartir y la preservación cultural. La práctica de las enfermeras, en estas comunidades, se construye a través del encuentro del individuo/familia/comunidad, el fortalecimiento del vínculo y el respeto y la apreciación de la cultura y las formas de vida de las personas. Se reitera una práctica de compartir la responsabilidad, en la dualidad construida entre quilombolas y profesionales. Conclusiones e implicaciones para la práctica: La práctica de las enfermeras en las comunidades de quilombolas se basa en el reconocimiento de las especificidades sociales y culturales de los grupos con antepasados del continente africano y contribuye a fortalecer la integración de la atención en el encuentro individuo-profesional con responsabilidades compartidas.

Palabras clave: Enfermería; Cultura; Estrategia de Salud Familiar; Grupo de ascendencia continental africana; Grupos Minoritarios. 


\section{INTRODUÇÃO}

A prática do enfermeiro no contexto da Estratégia Saúde da Família (ESF) acontece por meio do fortalecimento do vínculo e da corresponsabilização entre profissionais, indivíduos, famílias e coletividade. Nesse cenário, o enfermeiro vivencia o desafio de construir sua prática em um contexto de desigualdades socioeconômicas, culturais e religiosas.

A Ética Feminista, defendida por Margaret Walker, fundamentase no reconhecimento de desigualdades, em contexto sociais definidos, no sentido de dar-Ihes visibilidade e permitir reflexões morais sobre as maneiras de agir e interagir com responsabilidade, colaboração e justiça social nesses espaços. Para a interação entre os indivíduos, é importante considerar aspectos como valores morais, experiência humana e expressão de julgamento para a tomada de decisão em respostas apropriadas às pessoas de um contexto próprio. ${ }^{1}$ Reconhecer tais aspectos efetiva a corresponsabilização pelo cuidado. Ignorá-los pode criar barreiras assistenciais para grupos de pessoas com características diversas, sejam grupos minoritários, sejam grupos especiais que se distinguem por suas raízes culturais e étnicas.

Ao considerar grupos especiais, destacamos as comunidades remanescentes dos quilombos, definidos como grupo com ancestrais do continente africano. Essas comunidades possuem vínculo de parentesco e se organizam como grupo social, em resgate de sua humanidade, cultura e identidade., ${ }^{2,3}$ As comunidades remanescentes dos quilombos foram definidas pelo decreto $4.887 / 2003$, como grupos étnico-raciais autodeclarados que guardam relação com um território específico e ancestralidade negra, relacionada com a resistência à opressão sofrida ao longo da história. ${ }^{2}$

Esse contingente populacional vive em marginalização socioeconômica, ${ }^{4}$ apresentando precárias condições de vida e de saúde, índices de pobreza alarmantes, menor expectativa de vida ao nascer, bem como menor acesso aos serviços de saúde. Apresenta nível insatisfatório de assistência, maior mortalidade infantil e materna, além de pior percepção do estado de saúde em comparação com a população branca. 5,6 Outra questão importante é a existência do racismo, a qual incide, negativamente, em suas condições de vida, comprometendo, inclusive, o acesso aos serviços de saúde..$^{2,7}$

Walker ${ }^{1}$ pressupõe que, ao considerar grupos minoritários, é essencial conhecer as situações de vulnerabilidades e iniquidades vivenciadas, bem como a diversidade cultural e particularidades do contexto social. Nesse contexto, é fundamental analisar os lugares e as posições sociais que as pessoas ocupam na sociedade. ${ }^{1}$ Percebe-se então que, a atuação do enfermeiro no contexto de comunidades onde prevalecem grupos minoritários, deve ser desenvolvida no sentido de apreender situações singulares vivenciadas pela população.

Em sua atuação, o profissional deve reconhecer as particularidades de cada indivíduo/família e fortalecer o vínculo com esses sujeitos por meio do encontro. ${ }^{8}$ Desse modo, a prática do enfermeiro se configura no encontro constituído pelas trocas de saberes e respeito, possibilitando a participação efetiva e emancipação dos sujeitos na condução do cuidado. ${ }^{8}$ Esse agir, na perspectiva da Ética Feminista, deve ser permeado de responsabilidades, construído nas relações, reproduzindo reconhecimentos existentes ou transformando-os, promovendo inclusão social e eliminando formas de opressão e de dominação existentes no contexto social contemporâneo. ${ }^{1}$

O modelo em que a prática é construída, entendendo que os saberes e viveres dos sujeitos estão em consonância com a moralidade impregnada, compartilhada e reconhecida na comunidade, incita o relacionamento interpessoal construtivo e colaborativo para que as decisões façam sentido para as pessoas, promovendo autonomia do sujeito. Esse modelo, considerado por Walker ${ }^{1}$ como Expressivo-Colaborativo, é dinâmico e se conforma junto à moralidade da população, na qual valores, experiências e conhecimentos dos e entre os sujeitos constroem e sustentam a prática de responsabilidade, compartilhada em um espaço comum. A moralidade permite e requer das pessoas o entendimento acerca de si mesmas e dos seus relacionamentos no cotidiano, definidos por certos valores já instituídos no meio social. ${ }^{1}$

Diante do exposto, pressupõe-se que a construção da prática do enfermeiro em comunidades quilombolas deva acontecer dentro e junto às comunidades, de forma que o enfermeiro seja capaz de (re)conhecer as particularidades deste grupo populacional, a fim de direcionar suas ações em consonância com os valores e a cultura local. Nessa perspectiva, considerando as particularidades das comunidades quilombolas, surge a questão norteadora desse estudo: Como se dá a construção da prática do enfermeiro em comunidades quilombolas no contexto da ESF?

O objetivo desse estudo foi compreender as particularidades de comunidades quilombolas para a construção da prática do enfermeiro na Estratégia Saúde da Família, sob o prisma da Ética Feminista. Os resultados podem contribuir para uma prática profissional mais colaborativa e corresponsável, construída por meio de relações efetivas em um contexto social, visando o cuidado centrado no indivíduo, na família e na coletividade.

\section{MÉTODO}

Trata-se de um estudo de caso único integrado de abordagem qualitativa. A abordagem qualitativa é capaz de expor a complexidade da vida humana e evidenciar significados subjetivos da vida social. ${ }^{9}$ O estudo de caso, por sua vez, possibilita a compreensão de um fenômeno contemporâneo, social e complexo em seu contexto no mundo real. ${ }^{10}$ Neste estudo, o caso definido foi "a prática de enfermeiros em comunidades quilombolas".

Considerando a complexidade do caso em análise e a relação que se exige para a prática em grupos minoritários, utilizouse o referencial epistemológico da ética feminista defendido por Margaret Urban Walker. ${ }^{1}$ Este referencial diz respeito ao entendimento apropriado à filosofia moral e à análise reflexiva das formas de vida moral em um contexto social, revelando que a sociedade se sustenta em uma prática de responsabilidade mútua. ${ }^{1}$ Assim, a ética feminista pode fundamentar a análise crítica sobre a construção da prática de enfermeiro em comunidades 
quilombolas, assumindo-a como uma prática de responsabilidade compartilhada no entendimento da moralidade impregnada entre as pessoas. Isto porque a moralidade representa a consciência moral e social do sujeito em um determinado contexto, sendo concretizada no seu (re)conhecimento social mediante a dualidade entre os sujeitos. Desse modo, a prática é colaborativa e realizada no compartilhamento de conhecimentos e de valores, no reconhecimento das diferenças e das diferentes posições dos agentes sociais na comunidade.

O cenário deste estudo foram as ESF onde estão adscritas todas as 10 comunidades quilombolas da Região Metropolitana de Belo Horizonte, ${ }^{11}$ certificadas pela Fundação Cultural Palmares (FCP), ${ }^{12}$ sendo: quatro comunidades urbanas, três localizadas em Belo Horizonte (Comunidade quilombola dos Luízes, Manzo Ngunzo Kaiango e Mangueiras) e uma em Contagem (Comunidade Quilombola Arturos); e seis comunidades rurais, das quais três estão localizadas em Brumadinho (Quilombo de Sapé; Marinhos e, Ribeirão), duas em Jaboticatubas (Comunidade quilombola Mato do Tição e Açude) e uma em Pedro Leopoldo (Comunidade Quilombola de Pimentel). Conforme dados de 2019 do FCP, há 2.744 comunidades quilombolas no Brasil, sendo, em Minas Gerais, 301 comunidades. $^{12}$

A quantidade de participantes foi a totalidade de enfermeiros (sete) da equipe da ESF que atuava nas referidas comunidades, sendo: três enfermeiros de Belo Horizonte; um de Contagem; um de Brumadinho (que ele atende às três comunidades quilombolas do município); um de Pedro Leopoldo e um de Jaboticatubas. Não havia qualquer enfermeiro atuando em uma das comunidades localizadas em Jaboticatubas no período da coleta de dados. Participaram também 59 moradores dos quilombos cadastrados na ESF, residentes nas comunidades de Arturos (07), Marinhos (07), Ribeirão (08), Sapê (08), Açude (10), Mato do Tição (11), Pimentel (08), perfazendo o total de sete comunidades. O contato com as comunidades foi mediado pelos Agentes Comunitários de Saúde (ACS), os quais acionavam o líder da comunidade e discorriam sobre a pesquisa. Os líderes, então, ficaram responsáveis pelo convite e agendaram o dia e horário do encontro para àquelas que quiseram participar voluntariamente. $O$ quantitativo de participantes (amostra $=59$ ) foi definido pelo aceite das pessoas, sendo realizado um grupo para entrevista em cada comunidade. Os moradores das comunidades quilombolas de Belo Horizonte recusaram participar da entrevista coletiva, tendo sido realizadas visitas nesses locais com conversas informais com os líderes. Considerando que a amostra seria definida pelo desejo de as pessoas participarem, percebe-se que a adesão foi baixa. Contudo, os participantes presentes se integravam ao grupo, motivados a se expressarem, expondo suas vivências, sentimentos e valores, contribuindo para atender aos objetivos da pesquisa. $O$ critério de inclusão para os enfermeiros foi estar atuando na ESF no atendimento à comunidade quilombola e para os moradores, a de estar cadastrado na ESF.

A coleta de dados foi realizada no período de fevereiro a junho de 2018 mediante três fontes empíricas: observação direta e informal, a entrevista individual com os enfermeiros e a entrevista coletiva com os quilombolas.

A observação direta decorre sem a necessidade de roteiro previamente estabelecido, mantendo ampla perspectiva que permite valorizar os atores sociais, suas tradições e costumes, verbalizados ou evidenciados em gestos e atitudes e categorias de pensamento. ${ }^{13}$ A observação aconteceu nas Comunidades Quilombolas e nas unidades de ESF. Registrou-se aproximadamente, 60 horas de observação, anotadas em diário de campo, e identificadas nos resultados como Notas de Observação (NO), nas quais foram pontuadas as impressões da pesquisadora, como também resultados de conversas informais.

As entrevistas com os enfermeiros foram individuais, com tempo médio de duração de 30 minutos, com um roteiro de perguntas que versavam sobre as práticas desenvolvidas no quilombo, o reconhecimento acerca da comunidade, os obstáculos para efetivar a prática e as potencialidades do desenvolvimento do trabalho.

As entrevistas com os residentes quilombolas foram coletivas com duração média de 40 minutos por grupo e abordaram questões relacionadas ao significado de ser e viver na comunidade quilombola, com ênfase no atendimento de saúde.

Os depoimentos dos participantes, enfermeiros e quilombolas foram gravados e transcritos integralmente. Os dados empíricos derivados das entrevistas e as NO foram submetidas à Análise de Conteúdo. ${ }^{14}$ Para a análise, utilizou-se o Software Atlas.ti. 8.0® como ferramenta operacional para a organização dos dados, favorecendo a indexação, a busca e a teorização. ${ }^{15} \mathrm{~A}$ análise de conteúdo consiste em um conjunto de técnicas de análise das comunicações estabelecidas entre o pesquisador e participantes, visando a obtenção da essência dos relatos por procedimentos organizados com o objetivo de descrever o conteúdo das mensagens. Para essa análise, procedeu-se à organização em três etapas, sendo elas: pré-análise, exploração do material e o tratamento dos resultados e inferência e interpretação.

Na primeira etapa, pré-análise, momento em que se realizou leitura do corpus e extraiu as ideias principais. A segunda, exploração do material e tratamento dos resultados consistiu no desmembramento do texto em códigos - codes - e seu reagrupamento. A codificação foi realizada por meio de recorte, agregação e enumeração dos dados do texto e permitiu a representação do conteúdo ou de sua expressão. A terceira etapa, inferência e interpretação, correspondeu à fase final, na qual os dados categorizados foram tratados de forma a terem significados, a fim de aprofundar a análise e conferir maior densidade à investigação do fenômeno, estabelecendo diálogo com a literatura. ${ }^{14}$

O estudo respeitou as exigências da resolução 466/12 do Conselho Nacional de Saúde. O projeto foi aprovado pelo Comitê de Ética em Pesquisa da Universidade Federal de Minas Gerais (CAAE 71509317.0.0000.5149) e autorização, com Termo de Anuência, das Secretarias Municipais de Saúde dos municípios em questão. O Termo de Consentimento Livre e Esclarecido (TCLE) foi lido e assinado pelos participantes após explanação dos 
objetivos, riscos e benefícios da pesquisa e das fontes de coleta de dados. Para garantir o anonimato, os enfermeiros receberam a denominação de "ENF" seguida do número aleatório de 1 a 7 , e os grupos das entrevistas coletivas, além da denominação "QUILOMBO", também seguido da numeração aleatória de 1 a 7. Ressalta-se que o estudo seguiu os critérios do COREQ, as quais abrange os componentes necessários do desenho do estudo para a qualidade da pesquisa.

\section{RESULTADOS}

Os resultados apontaram que as particularidades das comunidades quilombolas estão relacionados à tradição, valores, história cultural e história ascendente. A prática, nesse contexto, foi construída de forma transversal, por meio de entendimento da moralidade, própria da comunidade quilombola e de suas responsabilidades sobre as demandas da comunidade, baseadas no respeito e reconhecimento de suas singularidades.

Os participantes quilombolas reforçaram as características e o vínculo de parentesco que perpetuam nos seus modos de viver, envolvendo expressões e manifestações culturais de música, de dança e de religião apreendidas dos antepassados e associadas à afrodescendência e à escravidão. Desse modo, percebe-se pelos depoimentos de QUILOMBO1 e QUILOMBO2 a preservação da cultura em um ciclo de continuidade entre gerações.

É uma origem que nosso avô deixou, eu sinto assim. Ser quilombola é origem dos nossos bisavôs, a matéria viva deles está aqui (QUILOMBO1)

Todo mundo que mora aqui é uma família. Éuma comunidade família. Para mim, ser quilombola é ser pessoa que vem de uma origem afrodescendente, que tem uma raiz, uma cultura que quer preservar, que quer continuar, passar para os filhos, para os netos, para os amigos, para as crianças que estão chegando aqui (QUILOMBO2)

Identificou-se que os quilombolas valorizam a cultura aprendida pelos antepassados como um resgate da própria história e fortalecimento do quilombo, que constituem a construção da moralidade da comunidade. Observou-se o desenvolvimento de atividades culturais e religiosas nas comunidades e o envolvimento de todos, inclusive, das crianças. No período da coleta de dados, a pesquisadora vivenciou a visita do Rei Ooni da região de lfé na Nigéria a uma das comunidades. Houve envolvimento dos quilombolas com os preparativos para a visita, a qual foi marcada por encontro cultural e confluência de saberes dos povos tradicionais de Matriz Africana, entre os povos Yorubás e a comunidade quilombola (NO).

A participação de crianças em festividades como a mencionada é valorizada e ensinada pelos pais. Outra forma de ensinar a tradição e a história da cultura afro-brasileira é a parceria da comunidade com a escola.
Igual eu falo, os pequenininhos parecem que vêm no sangue, eles já vêm tocando e quando começa ficam tudo doido. Esse aqui mesmo nunca vi, desse tamaninho gosta demais... (QUILOMBO5).

Desde a criancinha no útero, começam a participar das festas, todo mundo participa. As crianças participam. Ela faz caixa (tambor) pequenininha para as crianças (QUILOMBO7).

A gente vai na escola, também, para estar mostrando, contando um pouco, como que começou, como que o povo fazia, o que passou (QUILOMBO2).

Considerando o forte vínculo parentesco e de união entre os quilombolas, ENF3 percebe a importância da solidariedade entre eles, como forma de organização social, a qual é marcada pela cooperação entre as famílias.

O quilombo é muito organizado, são parentes, eles se ajudam. Tem um que tem carro, vai lá busca o outro que não tem. Tem muitos filhos, os patriarcas têm muitos filhos, a coisa se organiza bem. (ENF3)

O enfermeiro destaca a importância do reconhecimento do cotidiano da comunidade como organização social, no sentido de entender a moralidade impregnada no contexto em que vivem para construir uma prática de responsabilidade. Como organização social, viver na comunidade significa compartilhamento e união de aspectos culturais e religiosos.

A união, a tranquilidade de estar todo mundo junto. Qualquer coisa que precisa sempre tem alguém ajudando, preocupado com a gente. Sempre tem os diálogos, as conversas, a festa! Então, assim, tem muita união, a questão cultural também, a fé (QUILOMBO7).

Candomblé é uma festa cultural muito boa. Nossa senhora! É boa demais! Vem gente de todo canto e todo mundo adora a festa. É uma dança dos antigos, dos escravos. Na verdade, é nossa religião. Aqui tem a manifestação da religião católica, mas o candomblé que é a tradição que a comunidade carrega, ela foi herança dos escravos, dos negros escravos que foram nossos antepassados, nossa família (QUILOMBO5).

A questão cultural e a valorização religiosa pelos quilombolas são de tal maneira fortes que ENF3 as reconhece como constituintes das comunidades, como forma de aceitação pela comunidade e de fortalecimento da relação de confiança entre profissional-usuário e de realização da prática consoante à criação de vínculo com a comunidade.

A parte da religiosidade também é muito forte. Tem um senhor que é o benzedor. Aí pessoas da cidade, da região metropolitana, artistas, você chega lá tem fotos de todo 
mundo, vem gente de tudo que é lugar para benzer. Ele já é bem idoso. São muito ligados ao Congado, à Folia de reis. Eles sempre estão em eventos. (ENF3)

O reconhecimento das tradições e o respeito pela relação estabelecida é uma forma de promover a prática de responsabilidade e colaborativa, fortalecendo a assistência centrada nas necessidades da comunidade, com vistas à promoção de práticas de autocuidado, de manutenção da vida e de vínculo entre profissionais-usuários-família. Reconhecer os valores da comunidade é desenvolver a sensibilidade moral atentos à identidade, necessidades, emoções, motivos e desejos, que são próprios dos indivíduos em seu contexto social, nas diferenças de viver e pensar no mundo e na sua percepção e atitudes de saúde.

Uma ação para efetivar práticas de responsabilidade é a criação de vínculo. $O$ vínculo está diretamente ligado às atitudes e às sensibilidades do profissional em saber escutar e acolher o indivíduo/família. Os participantes sinalizaram que conviver diretamente com a comunidade e saber como lidar com ela é fundamental para a sua prática.

O enfermeiro é o papel fundamental, o que a gente faz, a gente lida direto com o paciente, é ligação direta, contato, é vinculo que a gente cria com a comunidade, é fundamental, não é? (ENF2).

Eu acho que é o jeito de acolher, o jeito de você falar, conversar, e entender, é a principal ação (ENF6).

Houve relatos que indicam fragilidades na conformação da comunidade devido à ausência de pertencimento de algumas pessoas ao grupo, à precariedade nos vínculos, à discriminação e à carência, em geral, frutos da negligência de políticas públicas e serviços assistenciais para os quilombolas. Em conversa informal com a pesquisadora, uma enfermeira afirmou que conhece apenas um neto de quilombola, sem apresentar, porém, qualquer atitude em relação ao reconhecimento da formação de grupos de remanescentes na região, a despeito de atuar na área de abrangência de uma comunidade (NO).

Agora tem gente que tem, como ele disse, tem preconceito de falar que é quilombola (QUILOMBOLA1).

Infelizmente, o quilombo é pobre, não tem ninguém rico aqui, mas nós fomos correndo atrás de uma coisa e outra, $e$ mesmo assim não tem reconhecimento (QUILOMBOLA6).

Para mim, eu acho que assim, aqui é uma comunidade em especial muito carente, carente de tudo, não só de dinheiro (ENF7).

Poderia ser diferente, eu sinto assim, não é de igual para igual, eu sinto que eles são um pouco discriminados, essa coisa enraizada mesmo, não sei, mas existe racismo sim. O povo aqui é esquecido, largado. (ENF2)
Assumir o preconceito e as injustas sociais vivenciadas pela comunidade quilombola, não somente na perspectiva de quem vive (quilombola), mas de quem convive (enfermeiro), significa reconhecer a situação de vulnerabilidade dessa comunidade e de manutenção do racismo, gerando situações de opressão e discriminação na população negra. Os fatores socioeconômicos e étnico-raciais, citados nos depoimentos, estão associados a determinantes sociais de saúde, os quais acarretam inequidades, interferindo nas condições de bem-estar da população.

A construção da prática do enfermeiro se faz de forma transversal no (re)conhecimento de valores, história, cultura e necessidades da comunidade quilombola, a fim de planejar estratégias dirigidas aos cuidados com a saúde da população negra, eliminando formas de opressão e invisibilidades sociais que acometem essa população. Diante do cenário o enfermeiro precisa construir sua prática fundamentada no senso de responsabilidade, respeito e justiça social, considerando o posicionamento do sujeito moral em seu contexto social, isto é, em uma prática de responsabilidade defendida pelo modelo expressivo-colaborativo.

\section{DISCUSSÃO}

O quilombo assume posição de destaque, no Brasil, representando o passado de um povo que resistiu ao sistema escravocrata, tornando-se uma forma de organização políticosocial e de identidade étnica. Distingue-se, pois, por elementos socialmente construídos e consolidados e por sua cultura e aspectos religiosos. ${ }^{16}$ No presente estudo, identificou-se que, para os quilombolas, o pertencimento a uma comunidade é motivo de orgulho, permitindo rememorar a história dos antepassados e manter viva sua história de lutas.

Para os participantes, a representação do quilombo assume dimensões para além da propriedade da terra, sendo a solidariedade, a organização como grupo social e os laços de parentescos consideradas traços identitários ${ }^{17}$ significativos da comunidade, reforçando, pois, seus laços de pertencimento. Chama a atenção a importância de viver em comunidade, de participar de eventos e de encontros que potencializam os canais de comunicação, e de união. O pertencimento à comunidade quilombola está atrelado aos laços estabelecidos entre as pessoas, bem como com a identificação cultural e com a espiritualidade. Apreende-se que os modos de viver nessas comunidades ditam as relações que se estabelecem com o espaço habitado, de maneira que o espaço físico serve de base para a construção de vínculos identitários de todo o grupo que coletivamente o constitui. ${ }^{18}$

A religião legitima e fortalece os laços familiares entre os quilombolas. Em muitos casos, as práticas religiosas se apresentam como um dos componentes essenciais para a manutenção e reprodução de práticas culturais. Desse modo, percebe-se que a relação do quilombola, assim como outras comunidades, vai além da posse da terra, ou seja, está ligada à fé e às relações em comunidade. ${ }^{19}$

A comunidade consiste, pois, na organização das pessoas em um dado território, com a configuração de grupo social, 
estabelecendo relações solidárias e buscando alcançar a liberdade e a dignidade. $\mathrm{O}$ uso coletivo da terra se configura como a base da uma sociedade fraterna e livre das formas mais cruéis de preconceito e desrespeito. ${ }^{20}$

O artigo $3^{\circ}$ decreto $n^{\circ} .6040 / 2007$, que estabelece a Política Nacional de Desenvolvimento Sustentável para Povos e Comunidades Tradicionais, define como Povos e Comunidades Tradicionais, grupos reconhecidos culturalmente, com formas próprias de organização social, ocupantes de territórios e recursos naturais para reprodução cultural, social, religiosa, ancestral e econômica, utilizando conhecimentos e práticas gerados e transmitidos pela tradição. ${ }^{21}$ Assim, a tradição pode ser reconhecida como guia e como forma de conhecimento transmitida entre gerações, sendo mutável com o passar do tempo. ${ }^{22}$

Estudo realizado em uma comunidade quilombola em Goiás mostrou que a participação das crianças nessa continuidade da tradição, principalmente na organização das festas, é fator um potencial de (re) interpretação da cultura, fazendo-a se perpetuar entre as gerações. Nessa perspectiva, as crianças reconhecem sua capacidade de renovar a própria cultura, fortalecendo os laços de identificação com o universo apresentado. ${ }^{23}$ Desse modo, as histórias são contadas e recontadas pelas gerações e transformadas ao longo do tempo. Por meio da cultura, os quilombolas expressam seus valores e princípios, vinculandoos de forma simbólica e afetiva ao grupo, o que permite aos moradores se sentirem pertencentes ao grupo, em um espaço de trocas e compartilhamentos. ${ }^{23}$

Considerar a solidariedade entre os quilombolas e a organização social do grupo é reconhecer que a história, tradição, valores e cultura constituem a sua moralidade, sendo esta culturalmente situada e socialmente reconhecida nos modos de viver em um dado contexto. ${ }^{1}$

Ressalta-se que a compreensão da história e da formação social dos grupos leva à construção de práticas focadas no atendimento às necessidades da população, sendo, pois, a prática do enfermeiro legitimada pela busca do entendimento dos modos de viver na comunidade quilombola e na criação de vínculo para o compartilhamento das tomadas de decisão em saúde. Em vista disso, a prática se constrói com base nas relações interpessoais para articulação do que se pode fazer e como fazer para atender as necessidades da população negra apoiadas no respeito. Isso se configura como uma prática de responsabilidade que sustenta a moralidade da comunidade $e$ defende esse modo de vida como próprio daquele lugar, assim é uma prática colaborativa e compartilhada entre os sujeitos. Entende que cada um é responsável pelas coisas e pessoas. Mas, só é responsável quando se conhece. ${ }^{1}$ Nesse sentido, o enfermeiro deve inserir, em sua prática, estratégias que visem a construção do conhecimento da comunidade, fortalecimento do vínculo para a prática do autocuidado e manutenção da saúde. ${ }^{24}$ Cabe ao profissional ser responsável e coerente no fazer, no modo como fazer e a quem direciona sua prática, tendo em vista também a responsabilidade dos sujeitos envolvidos no cuidado. O entendimento da moralidade e a visibilidade das situações em que a comunidade vive direciona a prática para promover a autonomia dos sujeitos.

Como barreira para o desenvolvimento da prática de responsabilidade, encontra-se o poder hegemônico e dominante arraigado na sociedade, o qual interfere nas relações e produz a invisibilidade das culturas subordinadas a esse poder. ${ }^{1}$ Assim, são produzidas e reproduzidas formas de opressão e de exclusão, impactando a dificuldade das pessoas em se situar no meio em que vivem..$^{1,25}$ Por mais fortalecidos que se encontrem os laços e as tradições na comunidade quilombola, esta encontra-se submetida a padrões sociais decorrentes do modelo hegemônico, podendo haver questionamentos de integrantes da comunidade acerca de características da afrodescendência, o que pode gerar ações de preconceito e discriminatórias entre eles, fragilizando o pertencimento à comunidade quilombola. Nesse sentido, diante das barreiras do poder dominante, o Modelo Expressivo-Colaborativo enfatiza que a prática precisa abarcar a responsabilidade moral pelo cuidado com a saúde e o social de modo mais amplo, o que é inerente ao posicionamento moral do enfermeiro dentro do sistema de saúde..$^{1,25}$

\section{CONSIDERAÇÕES FINAIS E IMPLICAÇÕES PARA A PRÁTICA}

Para os quilombolas, a identificação com a história a que pertencem, a manutenção da cultura e da religião é importante para o grupo. Faz-se, pois, necessária a sensibilização dos profissionais de saúde para aspectos específicos desse grupo populacional, com vistas ao atendimento coerente com a realidade apresentada.

Dessa forma, a prática do enfermeiro deve assumir um papel social significativo no sentido de valorizar a cultura e os valores, bem como eliminar as formas de opressão e o preconceito vivenciados pela população negra. Para tal, é imperioso conhecer os valores e saberes dos indivíduos e coletividade, além da situação de minoridade em que esse grupo se encontra. O enfermeiro deve, então, construir sua prática de modo a se posicionar moralmente diante da realidade apresentada, o que implica desenvolver sensibilidade moral desde a sua formação profissional. Ademais, esse desenvolvimento culmina na valorização da enfermagem enquanto compromisso social na Estratégia Saúde da Família.

O presente estudo pode fornecer subsídios para a análise da gestão do trabalho e de políticas com ênfase tanto na prática do enfermeiro quanto no atendimento à população negra. Nesse sentido, é essencial pôr em foco na gestão de pessoas para (re) valorizar e (re)significar a produção de subjetividades e prática de responsabilidade do enfermeiro na Estratégia Saúde da Família. Além disso, a prática precisa ser sustentada em políticas que garantam os direitos da população negra, viabilizando meios para que o enfermeiro configure suas ações em consonância com o Sistema Único de Saúde.

É importante, aqui, salientar a escassez de estudos sobre a temática em foco e suas limitações no âmbito das comunidades 
quilombolas, embora a Agenda Nacional de Prioridades de Pesquisa em Saúde destaca, como prioridade para pesquisa, a saúde da população negra, estabelecendo, portanto, a importância de mais estudos a respeito da situação de saúde das populações negras vivendo em remanescentes dos quilombos.

As limitações do estudo pautam-se no limite geográfico. Ressalta-se que escolha foi a região metropolitana de Belo Horizonte, Minas Gerais, Brasil. Dessa forma, sugere-se a realização de outros estudos em variadas regiões, uma vez que a organização do trabalho do enfermeiro e da Estratégia de Saúde da Família podem ter conotações diferentes. A limitação teórica se apresenta na complexidade da abordagem que pode levar a alguma incoerência com relação ao gênero que ainda é muito enfatizada. Outra limitação se refere às questões sociais identificadas, que são extremamente grandes para o profissional enfermeiro, individualmente, mudar, porém, sugerese uma formação profissional com ênfase em competências culturais, morais e políticas, para que o profissional seja capaz de adquirir responsabilidade moral diante da realidade que the for apresentada.

\section{FINANCIAMENTO}

O presente trabalho foi realizado com apoio da Coordenação de Aperfeiçoamento de Pessoal de Nível Superior - Brasil (CAPES) - Código de Financiamento 001. Concessão de bolsa de doutorado a Lilian Cristina Rezende.

Auxílio à Pesquisa "A prática profissional da equipe de saúde e de gestores no contexto da Rede de Atenção à Saúde sob o prisma dos valores ético-morais e do sofrimento moral", concedido pelo Conselho Nacional de Desenvolvimento Científico e Tecnológico (CNPq), processo ํㅜ 409239/2016-0, sob a coordenação da pesquisadora Maria José Menezes Brito.

Auxílio à pesquisa "Influencia da prática profissional da equipe e de gestores no contexto da atenção primária nas condições de saúde da população negra", concedido pela Fundação de Amparo a Pesquisa do Estado de Minas Gerais/ Programa Pesquisa para o SUS (FAPEMIG/PPSUS), processo no APQ-03779-17, sob a coordenação da pesquisadora Maria José Menezes Brito.

\section{CONTRIBUIÇÃO DOS AUTORES}

Desenho do estudo. Aquisição. análise de dados e interpretação dos resultados. Redação e revisão crítica do manuscrito. Aprovação da versão final do artigo. Responsabilidade por todos os aspectos do conteúdo e a integridade do artigo publicado. Lilian Cristina Rezende. Maria José Menezes Brito. Carolina da Silva Caram. Luana Silva Rezende. Kênia Lara da Silva

Análise de dados e interpretação dos resultados. Redação e revisão crítica do manuscrito. Aprovação da versão final do artigo. Responsabilidade por todos os aspectos do conteúdo e a integridade do artigo publicado. Carolina da Silva Caram. Luana Silva Rezende. Kênia Lara da Silva.

\section{EDITOR ASSOCIADO}

\author{
Maria Catarina Salvador da Motta
}

\section{REFERÊNCIAS}

1. Walker MU. Moral understandings: a feminist study in ethics. 2nd ed Oxford: Oxford University Press; 2007.

2. Ministério da Saúde (BR), Secretaria de Gestão Estratégica e Participativa, Departamento de Apoio à Gestão Participativa. Política Nacional de Saúde Integral da População Negra: uma política para o SUS [Internet]. 2. ed. Brasília: Ministério da Saúde; 2013 [citado 2020 jan 10]. Disponível em: http://bvsms.saude.gov.br/bvs/publicacoes/ politica_nacional_saude_integral_populacao.pdf

3. Soares AN, Morgan BS, Santos FBO, Matozinhos FP, Penna CMM Everyday health-related beliefs and practices among primary health care users. Rev Enferm UERJ [Internet]. 2014; [citado 2020 jan 10];22(1):83-88. Disponível em: https://www.e-publicacoes.uerj.br/ index.php/enfermagemuerj/article/view/11450/8988

4. Nunes NMS, Verdan TL, Jiménez LO. Policy of ethnic quotes in Brazil: inclusion by means of social isonomy. Interdisciplinary Scientific Journal. 2019;6(1):1-12. http://dx.doi.org/10.17115/2358-8411/v6n1a12.

5. Guerrero AFH, Silva DO, Toledo LMD, Guerrero JCH, Teixeira P. Infan mortality rates in quilombo areas of the Municipality of Santarém-Pará, Brazil. Saude Soc. 2007;16(2):103-10. http://dx.doi.org/10.1590/S010412902007000200010.

6. Bezerra VM, Andrade ACS, Medeiros DS, Caiaffa WT. Arterial prehypertension in slave-descendant communities in southeast Bahia State, Brazil. Cad Saude Publica. 2017;33(10):e00139516. http://dx.doi org/10.1590/0102-311x00139516. PMid:29091177.

7. Werneck J. Institutional racism and black population health. Saude Soc 2016 set;25(3):535-49. http://dx. doi.org/10.1590/s0104-129020162610.

8. Ayres JRCM. Cuidado: trabalho, interação e saber nas práticas de saúde. Rev Baiana Enferm. 2017;31(1). http://dx.doi.org/10.18471/ rbe.v31i1.21847.

9. Minayo MCS. Scientificity, generalization and dissemination of qualitative studies. Cien Saude Colet. 2017 jan;22(1):16-7. http://dx.doi. org/10.1590/1413-81232017221.30302016. PMid:28076523.

10. Yin RK. Case study research and applications: design and methods. 6th ed. Los Angeles: SAGE; 2018.

11. Região Metropolitana de Belo Horizonte. Informações do plano metropolitano [Internet]. 2019 [citado 2019 dez 18]. Disponível em: http://www.rmbh.org.br/rmbh.php

12. Portaria n. 238/2018 (BR). Certidões expedidas às comunidades remanescentes de quilombos (CRQs). Diário Oficial da União [periódico na internet], Brasília (DF), 1 out 2018 [citado 2019 out 15]. Disponível em: http://www.palmares.gov.br/?page_id=37551

13. Minayo MCDS, Costa AP. Fundamentos teóricos das técnicas de investigação qualitativa. Rev Lusof Educ [Internet]. 2018; [citado 2019 dez 18];40(40):139-53. Disponível em: https://revistas.ulusofona.pt/ index.php/rleducacao/article/view/6439

14. Bardin L. Análise de conteúdo. São Paulo: Edições 70; 2011.

15. Brito MJM, Caram CS, Montenegro LC, Rezende LC, Rennó HMS Ramos FRS. Potentialities of Atlas.ti for data analysis in qualitative research in nursing. In: Costa AP, Reis LPR, Sousa FN, Moreira A, Lamas $\mathrm{D}$, organizadores. Computer supported qualitative research: studies in systems, decision and control. Switzerland: Springer; 2016. p. 75-84. (Studies in Systems, Decision and Control; vol. 71). https:// doi.org/10.1007/978-3-319-43271-7_7.

16. Vieira ABD, Monteiro PSM. Quilombola community: analysis of the persistent problem in health attention under the focus of the Intervention Bioethics. Saúde Debate. 2013;37(99):610-8. http://dx.doi.org/10.1590/ S0103-11042013000400008.

17. Brito MJM, Lara MO, Soares EG, Alves M, Melo MCDOL. Traços identitários da enfermeira-gerente em hospitais privados de Belo Horizonte, Brasil. Saude Soc. 2008;17(2):45-57. http://dx.doi.org/10.1590/ S0104-12902008000200006. 
18. Vogt GC. O artigo 68 do Ato das Disposições Constitucionais Transitórias (ADCT) como instrumento de reparação: território, identidade e políticas de reconhecimento. Rev O Social em Questão [Internet]. 2014; [citado 2020 jan 10];32:151-64. Disponível em: http://osocialemquestao.ser. puc-rio.br/media/OSQ_32_7_Vogt_WEB.pdf

19. Custódio ES, Costa CS. Religião, ética e educação: experiências e vivências do Quilombo do Mel da Pedreira no Amapá. Conjectura: Filos. Educ. 2018;23(especial):96-117. http://dx.doi.org/10.18226/21784612. V23.ESPECIAL.4.

20. Maia J. Herança quilombola maranhense: história e estórias. São Paulo: Paulinas; 2012.

21. Decreto n. 6040, de 7 de fevereiro de 2007 (BR). Institui a Política Nacional de Desenvolvimento Sustentável dos Povos e Comunidades Tradicionais. Diário Oficial da União [periódico na internet], Brasília (DF),
8 fev 2007 [citado 2019 dez 15]. Disponível em: http://www.planalto. gov.br/ccivil_03/_ato2007-2010/2007/decreto/d6040.htm

22. Shils E. Tradition. Chicago: The University of Chicago Press; 1981.

23. Furtado MB, Pedroza RLS, Alves CB. Cultura, identidad y subjetividad quilombola: una lectura a partir de la psicología cultural. Psicol Soc. 2014;26(1):106-15. http://dx.doi.org/10.1590/S0102-71822014000100012.

24. Meneses RCTD, Zeni PF, Oliveira CCDC, Melo CMD. Health promotion in a northeastern quilombola population - analysis of an educational intervention. Esc. Anna Nery Rev. Enfermagem. 2015;19(1):132-9. http://dx.doi.org/10.5935/1414-8145.20150018.

25. Liaschenko J, Peter E. Feminist ethics: way of doing ethics. In: Davis AJ, Tschudin V, Raeve L, organizadores. Essentials of teaching and learning in nursing ethics: perspectives and methods. Toronto: Elsevier; 2006. p. 181-190. a Artigo extraído da tese de doutorado "Prática de enfermeiros da equipe da Estratégia Saúde da Família em comunidades quilombolas sob o prisma da
ética feminista" apresentada ao Programa de Pós-Graduação em Enfermagem da Universidade Federal de Minas Gerais. Autoria de Lilian Cristina Rezende 